\title{
Stiffness model of machine tool supports using contact stiffness
}

$\operatorname{AUTHOR}(S)$ :

Kono, Daisuke; Inagaki, Takahiro; Matsubara, Atsushi; Yamaji, Iwao

CITATION:

Kono, Daisuke ... [et al]. Stiffness model of machine tool supports using contact stiffness. Precision Engineering 2013, 37(3): 650-657

ISSUE DATE:

2013-07

URL:

http://hdl.handle.net/2433/174061

RIGHT:

(c) 2013 Elsevier Inc:; この論文は出版社版でありません。引用の際には 出版社版をご確認ご利用ください。; This is not the published version. Please cite only the published version. 


\title{
Stiffness model of machine tool supports using contact stiffness
}

\author{
Daisuke Kono, Takahiro Inagaki, Atsushi Matsubara, Iwao Yamaji \\ Dept. of Micro Engineering, Graduate School of Engineering, Kyoto University \\ Yoshida-honmachi, Sakyo-ku, Kyoto 606-8501, Japan \\ Email: kono@prec.kyoto-u.ac.jp \\ Phone: $+81-75-753-5226$ \\ Fax: $+81-75-753-5226$
}

\begin{abstract}
The stiffness of machine tool supports should be properly designed for reducing both the ground disturbance vibration and the drive disturbance vibration. However, the stiffness cannot be easily calculated from the geometry and material properties of the support. In this paper, a 3D stiffness model of a machine tool support is proposed using contact stiffness. The stiffness in each direction is assumed to be determined by the contact stiffness at the interfaces and the bulk stiffnesses of the supports and the floor. The contact stiffness model proposed by Shimizu et al. is expanded to determine the contact stiffness in the normal and tangential directions of an interface. In the proposed model, the contact stiffness is obtained by multiplying the unit contact stiffness by the real contact area. The contact stiffness of concrete is experimentally investigated to estimate the stiffness between machine tool supports and the floor, and it was observed to be the primary determinant of the stiffness of interfaces between metal and concrete. Moreover, the unit contact stiffness of concrete is discovered to be less than $1 / 10$ of those of the metals that were used for the study. The natural frequency and vibration mode shape of a model machine tool bed are also experimentally measured and used to verify the proposed stiffness model. The comparison of the results obtained from the two procedures shows that the natural frequency and vibration mode shape of a machine tool bed can be predicted using the proposed stiffness model.
\end{abstract}

Keywords: stiffness model, support stiffness, contact stiffness, concrete, machine tool 
Nomenclature

W normal load

$W_{\text {pre }} \quad$ normal preload

$W_{v} \quad$ variable normal load

$F \quad$ tangential load

$k_{n} \quad$ normal contact stiffness

$k_{t} \quad$ tangential contact stiffness

$k_{n m c} \quad$ normal contact stiffness between the middle specimen and the lower specimen of the metal-concrete specimen set

$k_{n m m} \quad$ normal contact stiffness between the middle specimen and the lower specimen of the metal-metal specimen set

$\delta k_{n} \quad$ unit normal contact stiffness

$\delta k_{t} \quad$ unit tangential contact stiffness

$\delta k_{n c} \quad$ unit normal contact stiffness of concrete

$\delta k_{n m} \quad$ unit normal contact stiffness of metal

$\delta k_{t c} \quad$ unit tangential contact stiffness of concrete

$\delta k_{n 1}, \delta k_{n 2} \quad$ unit normal contact stiffnesses of materials 1 and 2

$\delta k_{t 1}, \delta k_{t 2} \quad$ unit tangential contact stiffnesses of materials 1 and 2

$i \quad$ subscript representing normal and tangential directions

$K_{n l} \quad$ normal stiffness of the lower specimen

$K_{n u} \quad$ normal stiffness of the upper specimen

$K_{n m c} \quad$ normal stiffness between the upper specimen and the lower specimens of the metal-concrete specimen set

$K_{n m m}$ normal stiffness between the upper specimen and the lower specimen of the metal-metal specimen set

$p_{m} \quad$ yield pressure

$A_{r} \quad$ real contact area

$A_{r m c} \quad$ real contact area between the middle specimen and the lower specimen of the metal-concrete specimen set

$A_{\text {rmm }}$ real contact area between the middle specimen and the lower specimen of the metal-metal specimen set

$d_{n l} \quad$ normal displacement of the lower specimen

$d_{n u} \quad$ normal displacement of the upper specimen 


\section{Introduction}

There has been a demand for higher efficiency in high-precision machining in recent times. Vibration of machine tools, such as those that result in the relative displacement of the tool and the table, pose a huge challenge to high-precision machining. Machine tool vibrations are classified into two types, namely, (1) ground disturbance vibration transmitted by the floor on which the machine is installed, and (2) drive disturbance vibration generated by the feed drives. Both types of vibrations are greatly determined by the stiffness of the machine tool supports.

Ground disturbance vibration can be reduced by using soft supports such as rubbers and air springs [1-4]. Unfortunately, soft supports also cause the entire machine to rock, thereby increasing the drive disturbance vibration [1]. The stiffness of machine tool supports should therefore be designed by taking into consideration the amplitudes of both types of vibration.

However, owing to the fact that the factors that determine the stiffness of machine tool supports have not been clarified, they have only been designed empirically by most machine tool builders. Moreover, since the stiffness of the support cannot be easily calculated from its geometry and material properties, it would have to be modeled on the basis of other factors to aid systematic design.

Some studies have shown that the stiffness at the interface (contact stiffness) of a support significantly affects the overall stiffness of the support [5,6]. Hoshi particularly noted that contact stiffness with the concrete floor is the most important factor that determines the stiffness of a support [5].

There have actually been many studies on contact stiffness. Theoretical models have been proposed on the basis of the Hertz theory, and the governing equation of the contact stiffness were derived [7,8]. The contact stiffness has also been measured in directions normal and tangential to the interface to verify proposed models [9-11]. Furthermore, the influence of surface topography on contact stiffness has been investigated [12]. While these experimental studies examined contact stiffness between the same type of materials (mostly steel), machine tool supports usually involve contact between different types of materials such as cast iron, steel, and concrete. The contact stiffness between metals and concrete is particularly of interest because concrete is the usual material used for the floor of workshops and factories. Shimizu et al. proposed a simple model of the contact stiffness at the interface of different materials and measured the stiffness normal to the interface for several combinations of materials [13].

In this paper, a model of the stiffness of a machine tool support is proposed on the basis of Shimizu et al.'s contact stiffness model. The model is then used to estimate the contact stiffness of interfaces between several metals and concrete in directions normal and tangential to the interface. Finally, the estimates of the proposed model are experimentally verified using a small model of a machine tool bed.

\section{Model of machine tool supports and contact stiffness \\ 2.1 Stiffness model of machine tool supports}

Figure 1 shows examples of machine tool supports. Medium- and small-sized machine tools are generally mounted on concrete floors with the aid of screw jacks or leveling blocks. Such height adjustment supports are used to ensure that the machine is leveled when installed. 


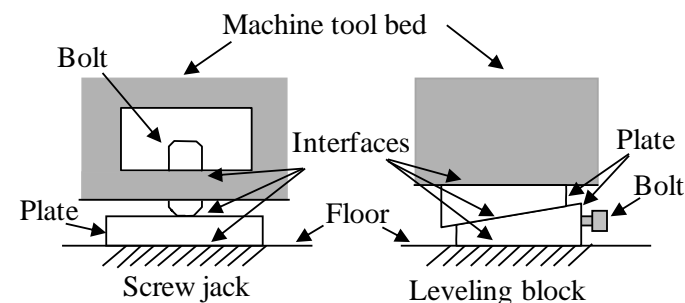

(a) Examples of machine tool support

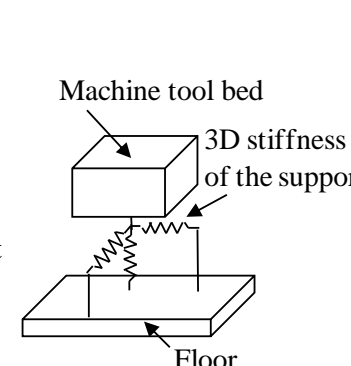

(b) 3D stiffness model of the support

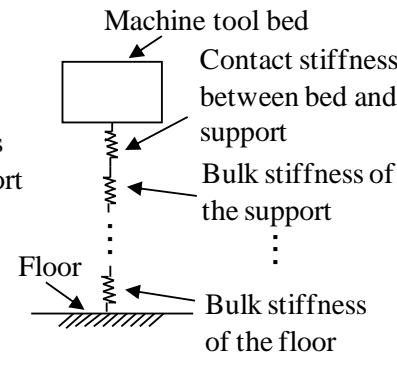

(c) 1D stiffness model involving bulk and contact stiffness

Fig. 1 Machine tool support and its model

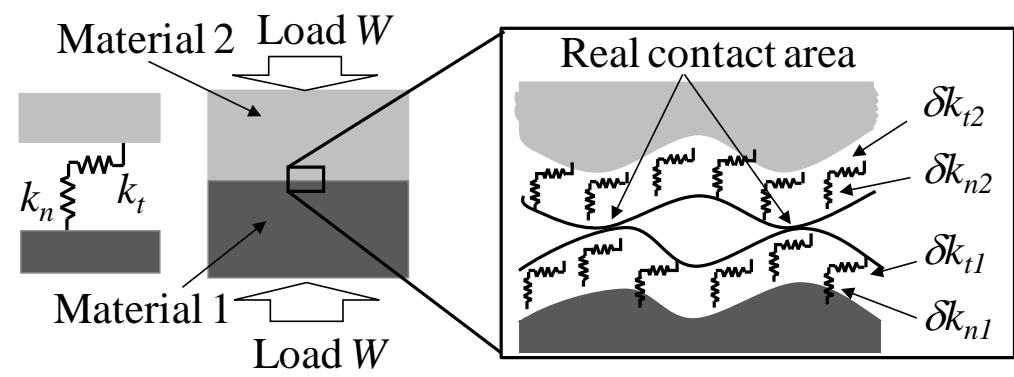

(a) Contact stiffness in the support (b) Unit contact stiffness model at the interface

Fig. 2 Model of contact stiffness

In this study, the stiffness of one support is modeled in 3D as shown in Fig. 1(b). The stiffness in each direction is assumed to be determined by the contact stiffness at the interface and the bulk stiffnesses of the support and floor. Hence, the stiffness in each direction is modeled by the bulk stiffness and the contact stiffness connected in series, as shown in Fig. 1(c). The bulk stiffness can be calculated from the modulus of elasticity and the geometry of the support. In this study, the contact stiffness is treated as a linear stiffness. A model of the contact stiffness is described in the following section.

\subsection{Model of contact stiffness}

The contact stiffness model proposed by Shimizu et al. [13] is modified here. Figure 2(a) shows a schematic of two materials in contact at the machine tool support. The load $W$ acts on the interface; $k_{n}$ and $k_{t}$ are the contact stiffnesses in directions normal and tangential to the interface, respectively.

In Shimizu et al.'s model, $k_{n}$ is considered to be the contact stiffness associated with a series of coupled springs spread over the interface. In this study, this model is expanded to obtain $k_{t}$ as shown in Fig. 2(b). $\delta k_{n 1}$ and $\delta k_{n 2}$ are the normal contact stiffnesses per unit real contact area (unit normal contact stiffness) of materials 1 and 2, respectively; and $\delta k_{t 1}$ and $\delta k_{t 2}$ are the tangential contact stiffnesses per unit real contact area (unit tangential contact stiffness). The real contact area is determined by the contacting roughness asperity of the interface. $k_{i}(i=n, t)$ is given by 


$$
k_{i}=\frac{\delta k_{i 1} \delta k_{i 2}}{\left(\delta k_{i 1}+\delta k_{i 2}\right)} A_{r}
$$

where $A_{r}$ is the real contact area and the subscript $i$ represents the normal or tangential direction. $A_{r}$ is given by

$$
A_{r}=\frac{W}{p_{m}}
$$

where $p_{m}$ is the lower of the yield pressures of materials 1 and 2 [14]. In this study, the yield pressure is assumed to be equal to the Vickers hardness.

From Eq. 1 and Eq.2, we see that $k_{i}$ is a nonlinear stiffness dependent on $W$. This is because the plastic deformation of the interface increases $A_{r}$. In the machine tool support, $W$ is determined by the steady load corresponding to the weight of the machine tool and the variable load corresponding to the drive disturbance caused by the drives of the machine. Considering that the steady load is generally much greater than the variable load, the latter can be neglected and the contact stiffness is treated as a linear stiffness.

\section{Estimation of unit contact stiffness for concrete}

$\delta k_{n}$ and $\delta k_{t}$ are required to estimate the contact stiffness using the proposed model. In our previous work, $\delta k_{n}$ and $\delta k_{t}$ were given for several metals usually used for machine tool support [15]. In this study, $\delta k_{n}$ and $\delta k_{t}$ are experimentally measured for concrete.

\subsection{Estimation method}

Figure 3 shows the specimen set used for the measurement. The set comprised upper, middle, and lower specimens. The contact stiffness values between the middle specimen and the other two specimens can be measured at two interfaces. Different materials are used for the specimens in order to estimate the contact stiffness for different combinations of materials. The dimensions of the middle specimen were chosen such that the real contact area would be less than the nominal contact area under a normal load of $10 \mathrm{kN}$, which was considered typical of the load on the supports of a small machine tool.

The contact stiffness of the specimen set is obtained from the stiffness between the

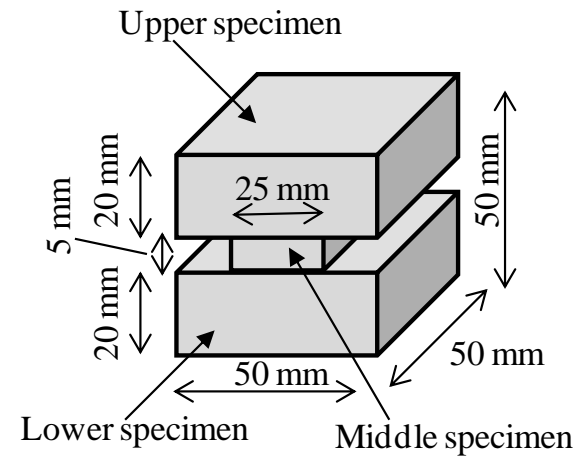

Fig. 3 Specimen set used in the measurement

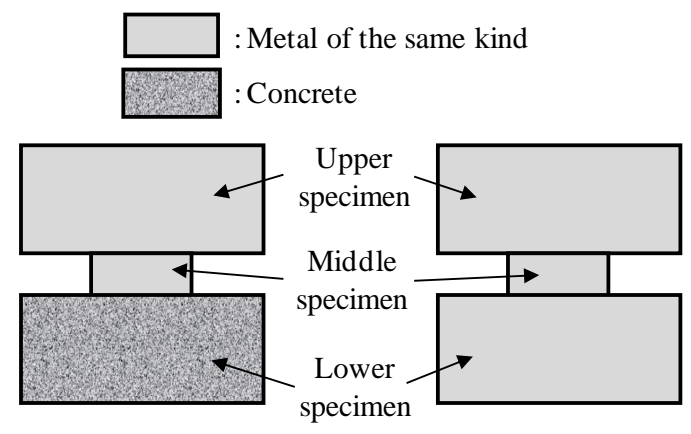

$\begin{array}{cc}\text { (a) Metal-concrete } & \text { (b) Metal-metal } \\ \text { specimen set } & \text { specimen set }\end{array}$ Fig. 4 Material combinations of the specimen set 
upper and lower specimens. As described in the following section, the stiffness between the upper specimen and the lower specimen consists of contact stiffness and bulk stiffness. The contact stiffness is typically determined by comparing the stiffness of the specimen set with that of a monolithic specimen that has no interface [15]. However, because it is difficult to produce a monolithic specimen from brittle concrete, a different method is used in this study.

The different combinations of the specimen materials that are used are shown in Fig. 4. Measurements are taken for a metal-concrete specimen set in which the lower specimen is made of concrete (Fig. 4(a)) and a metal-metal specimen set comprising specimens of the same kind of metal (Fig. 4(b)). Measurement results for these specimen sets are compared to determine the contact stiffness between the middle specimen and the lower specimen of the metal-concrete specimen set. The details of the procedure used to obtain $\delta k_{n}$ are given below.

\subsubsection{Measurement with metal-concrete specimen set}

The normal stiffness $K_{n m c}$ between the upper and lower specimens of the metal-concrete specimen set is measured. A schematic of the measurement is shown in Fig. 5. A steady normal load $W_{\text {pre }}$ is preloaded on the upper specimen and the normal displacements $d_{n l}$ and $d_{n u}$ of the lower and upper specimens are measured while the normal load $W_{v}$ is cyclically loaded and unloaded on the upper specimen. The stiffness $K_{n l}$ of the lower specimen is calculated from the relationship between $d_{n l}$ and $W_{v}$. The relationship between $d_{n l}$ and $W_{v}$ during the unloading is used to eliminate the effect of plastic deformation of the specimens. Similarly, the stiffness $K_{n u}$ of the upper specimen is calculated from $d_{n u}$ and $W_{v} . K_{n m c}$ is then calculated using

$$
K_{n m c}=\frac{K_{n u} K_{n l}}{K_{n l}-K_{n u}}
$$

\subsubsection{Measurement with metal-metal specimen set}

$K_{n m c}$ is the resultant stiffness of the contact stiffness at the two interfaces and the bulk stiffness of the specimens. Therefore, the stiffness $K_{n m m}$ between the upper and lower specimens of the metal-metal specimen set is obtained to determine the contact stiffness between the middle specimen and the lower specimen of both specimen sets. A similar method as explained in Section 3.1.1 is used to obtain $K_{n m m}$.

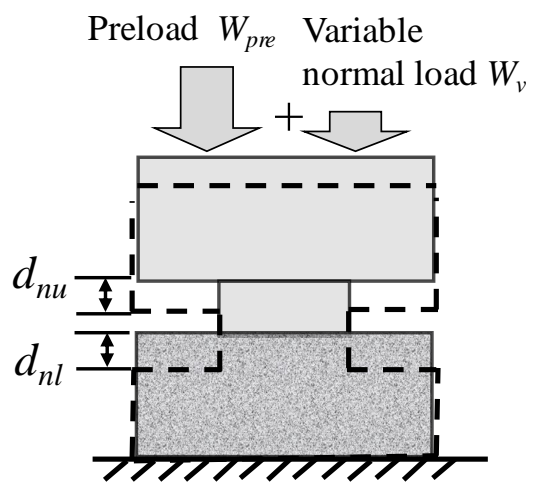

Fig. 5 Schematic of measurement in the normal direction 


\subsubsection{Calculation of contact stiffness}

The contact stiffness between the middle specimen and the lower specimen of both specimen sets is determined using the following relation:

$$
\frac{1}{K_{n m c}}-\frac{1}{K_{n m m}}=\frac{1}{k_{n m c}}-\frac{1}{k_{n m m}}
$$

where $k_{n m c}$ and $k_{n m m}$ are the normal contact stiffnesses between the middle specimen and the lower specimen of the metal-concrete and the metal-metal specimen sets, respectively. By substituting Eq.1 into Eq.4, we get the unit normal contact stiffness $\delta k_{n c}$ of concrete as

$$
\delta k_{n c}=\frac{1}{A_{r m c}}\left(\frac{1}{K_{n m c}}-\frac{1}{K_{n m m}}+\frac{2}{\delta k_{n m} \cdot A_{r m m}}-\frac{1}{\delta k_{n m} \cdot A_{r m c}}\right)^{-1}
$$

where $\delta k_{n m}$ is the unit normal contact stiffness of the metal, $A_{r m c}$ is the real contact area between the middle specimen and the lower specimen of the metal-concrete specimen set, and $A_{r m m}$ is the real contact area between the middle specimen and the lower specimen of the metal-metal specimen set. Strictly speaking, $\delta k_{n c}$ determined from this experiment include the difference between the bulk stiffnesses of concrete and metal.

The unit tangential contact stiffness $\delta k_{t c}$ of concrete is obtained through a procedure similar to that described in Sections 3.1.1-3.1.3. $W_{\text {pre }}$ is initially preloaded on the upper specimen, but a tangential load $F$ is loaded instead of $W_{v}$. The tangential displacements of the upper and lower specimens are measured.

\subsection{Measurement device and experimental conditions}

Figure 6 shows the setup of the experiment. The specimen is mounted on the compression testing machine (SHIMADZU) to apply a normal load. The normal load is applied through a steel ball to minimize the tilting of the specimen. The normal load is measured using a load cell installed on the testing machine.

In the measurement in the normal direction shown in Fig. 6(a), the normal displacement of the specimen is measured with an electric micrometer mounted with a

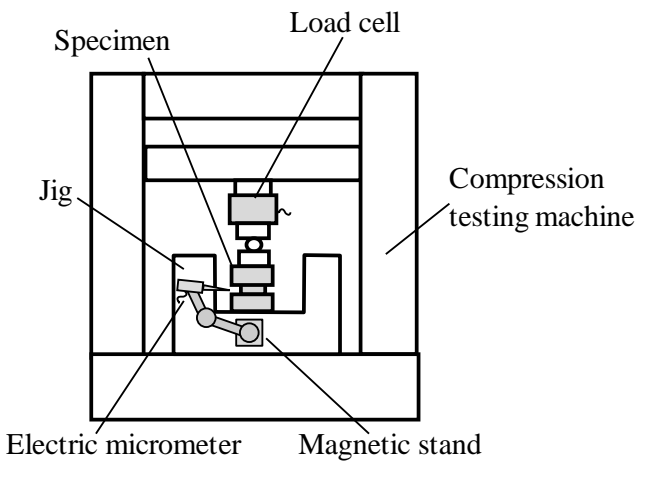

(a) Measurement in the normal direction

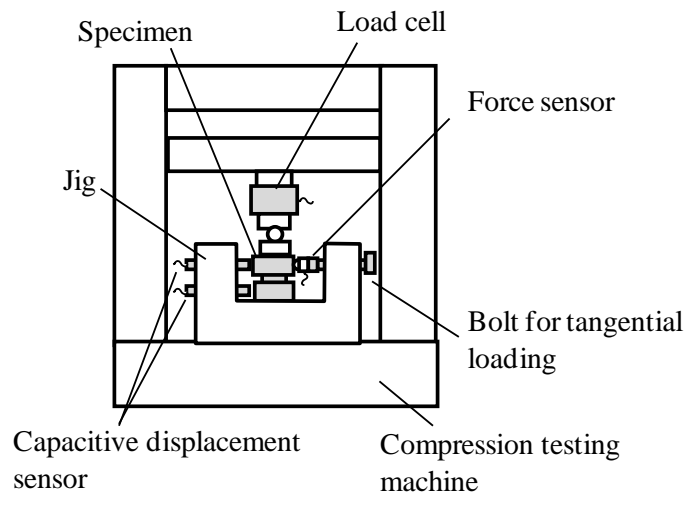

(b) Measurement in the tangential direction

Fig. 6 Schematic of measurement setup 
Table 1 Specifications of measuring instruments

\begin{tabular}{ccc}
\hline Force sensor & Measuring range & $\pm 5 \mathrm{kN}$ \\
& Accuracy & $\pm 1 \%$ \\
\hline \multirow{2}{*}{ Load cell } & Measuring range & $\pm 10 \mathrm{kN}$ \\
& Accuracy & $\pm 0.02 \%$ \\
\hline Capacitive & Measuring range & $\pm 250 \mu \mathrm{m}$ \\
displacement & Accuracy & $\pm 1 \%$ \\
\hline
\end{tabular}

Table 2 Specifications of specimens

\begin{tabular}{c|c|c|c|c}
\hline Material & S50C & SS400 & FC250 & Concrete \\
\hline Longitudinal elastic modulus GPa & 205 & 206 & 127 & $25-40$ \\
\hline Measured Vickers hardness kgf/mm & 230 & 180 & 230 & $\begin{array}{c}56 \text { (mortar) } \\
1470 \text { (gravel) }\end{array}$ \\
\hline Measured surface roughness Rz $\mu \mathrm{m}$ & 4.0 & 1.1 & 1.5 & 3.6 \\
\hline Unit normal contact stiffness $\delta k_{n} \mathrm{~N} / \mathrm{mm} / \mathrm{mm}^{2}$ & $\begin{array}{c}1.4 \times \\
10^{7}\end{array}$ & $\begin{array}{c}1.8 \times \\
10^{7}\end{array}$ & $\begin{array}{c}1.0 \times \\
10^{7}\end{array}$ & Not measured \\
\hline Unit tangential contact stiffness $\delta k_{t} \mathrm{~N} / \mathrm{mm} / \mathrm{mm}^{2}$ & $\begin{array}{c}1.6 \times \\
10^{6}\end{array}$ & $\begin{array}{c}1.6 \times \\
10^{6}\end{array}$ & $\begin{array}{c}2.0 \times \\
10^{6}\end{array}$ & Not measured \\
\hline
\end{tabular}

magnetic stand on the jig below the specimen. The stiffness is measured on the left and right sides of the middle specimen and the average value is used to minimize the effect of tilting of the specimen.

In the measurement in the tangential direction shown in Fig. 6(b), a tangential load is applied through a bolt, which is measured using a force sensor (Kistler). The tangential displacement of the specimen is measured with a capacitive displacement sensor (Lion Precision). Block gauges are fixed to the specimens as targets for the sensor. The specifications of the measuring instruments are listed in Table 1.

Carbon steel S50C, low alloy steel SS400, and cast iron FC250 are used as the metal specimens. Their specifications are given in Table 2. The values of $\delta k_{n}$ and $\delta k_{t}$ obtained in a previous work [15] are also given for the three metal specimens. The surface roughness of the specimens was measured with a contact-type surface roughness measuring machine. The surface of the concrete specimen was ground and polished. Since the Vickers hardness of the mortar in the concrete specimen was lower than that of the gravel in it, $A_{r m c}$ is calculated using the Vickers hardness of mortar. All the surfaces of the specimens are cleaned with ethanol in preparation for the experiment.

To eliminate the effect of plastic deformation, a normal load of $10 \mathrm{kN}$ is applied on the specimens for about $10 \mathrm{~min}$. before measurements are performed. While measuring in the normal direction, a $W_{\text {pre }}$ of $9 \mathrm{kN}$ and $W_{v}$ of $\pm 1 \mathrm{kN}$ are applied on the specimen sets. While measuring in the tangential direction, the maximum value of $F$ is set to $1 \mathrm{kN}$ for a $W_{\text {pre }}$ of $10 \mathrm{kN}$. The cyclic process of loading and unloading are repeated five times. The sampling frequency of the measurement is set to $100 \mathrm{~Hz}$. 


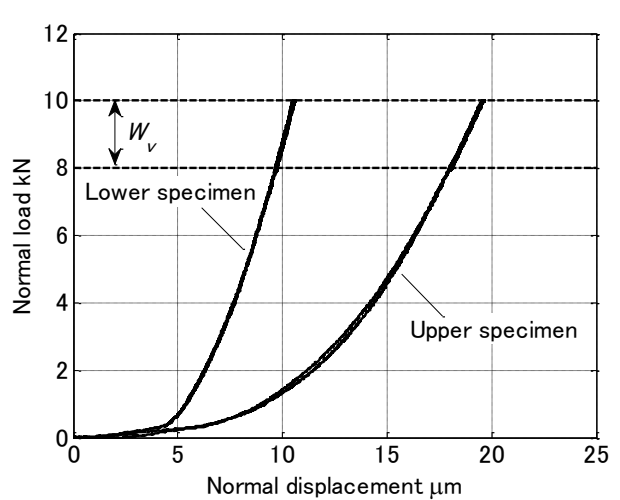

Fig.7 Relationship between normal displacement and load for the metal-concrete specimen set. The material of the metal specimen is S50C.

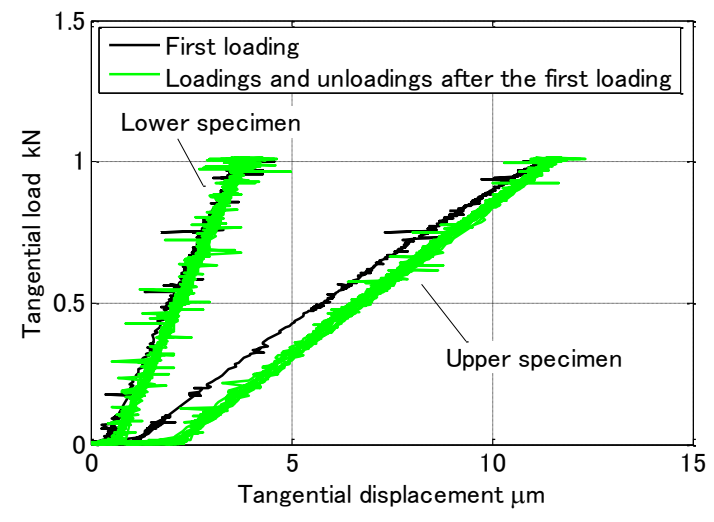

Fig.8 Relationship between tangential displacement and load for the metal-concrete specimen set. The material of the metal specimen is S50C.

\subsection{Experimental result}

Figure 7 shows the relationship between the normal load, comprising $W_{\text {pre }}$ and $W_{v}$, and the normal displacement of the left side of the metal-concrete specimen set, in which S50C is the metal. A nonlinear relationship is observed in all the relationships for preloading. The nonlinearity is due to the increase in the real contact area resulting from the elastic deformation of the interface. Thornley et al. also reported a similar relationship in their article [12]. Because the relationship is approximately linear for values of $W_{v}, K_{n u}$ and $K_{n l}$ were obtained by the least-squares fitting method.

Figure 8 shows the relationship between the tangential load and the tangential displacement for the metal-concrete specimen set. A linear relationship is observed here because the real contact area did not change when loading in the tangential direction. The tangential stiffnesses of the upper and lower specimens were therefore also obtained by the least-squares fitting method. As can be observed, the curve of the first loading of the upper specimen differs from those of subsequent loading and unloading, which is the result of the plastic deformation of the interface after the first loading. Although the normal preload that primarily determined the real contact area was constant, there was still a small increase in the contact area as a result of the tangential load. Tangential displacements of $2 \mu \mathrm{m}$ and $0.5 \mu \mathrm{m}$ resulting from plastic deformation are observed in the upper and lower specimens, respectively. 


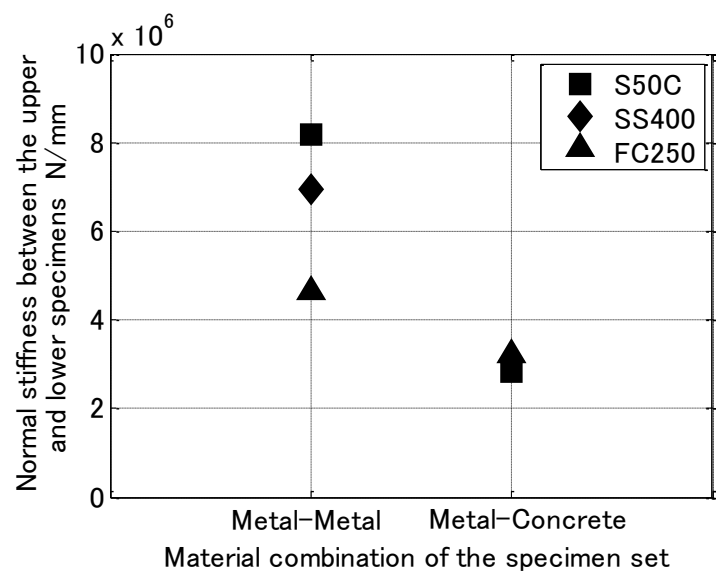

Fig. 9 Comparison of normal stiffness between the upper and lower specimens

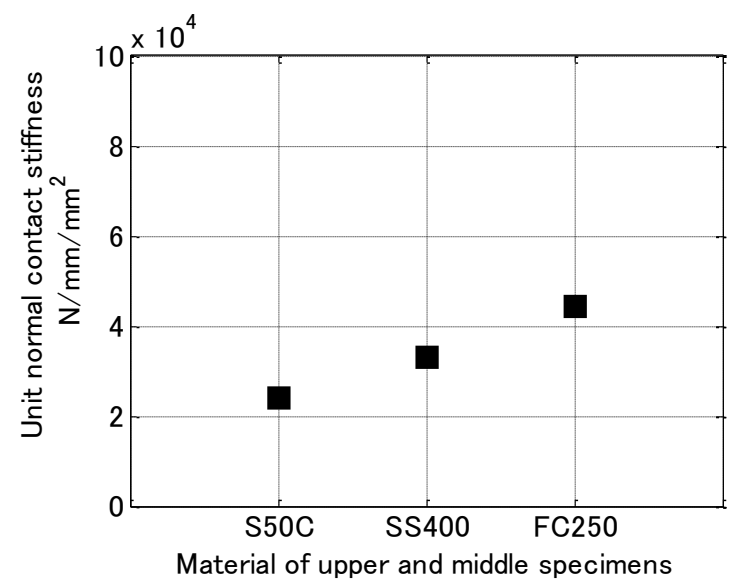

Fig. 11 Unit normal contact stiffness of concrete

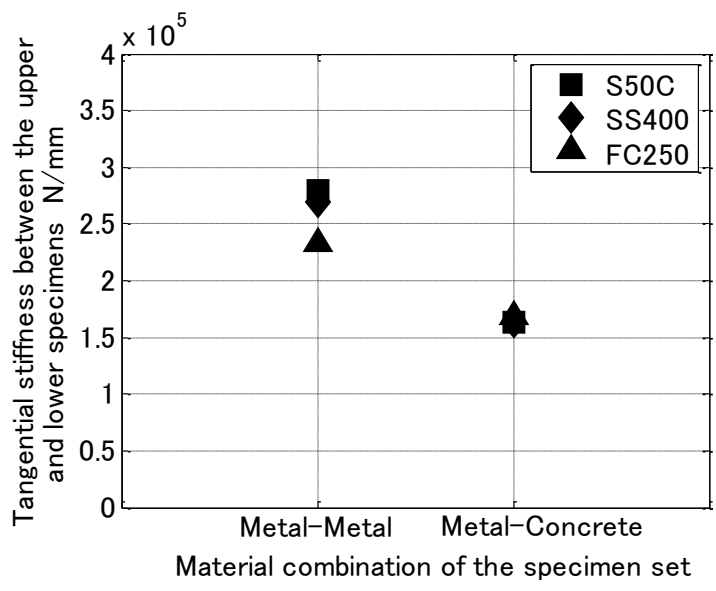

Fig. 10 Comparison of tangential stiffness between the upper and lower specimens

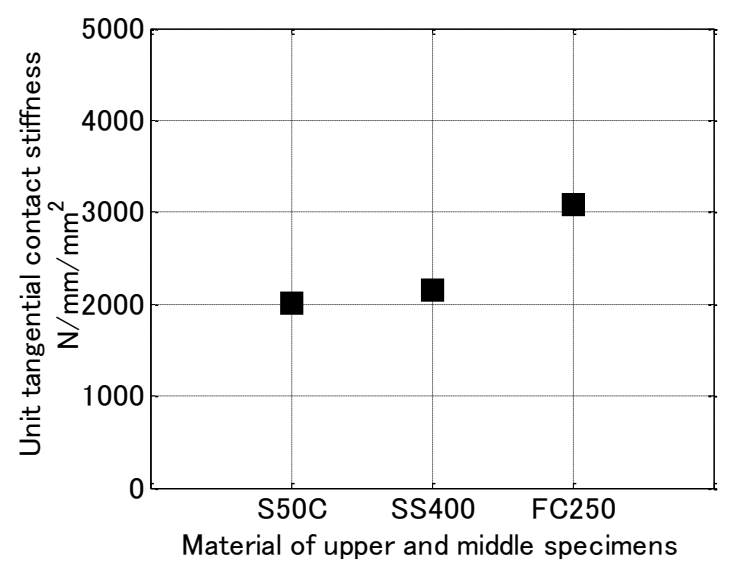

Fig. 12 Unit tangential contact stiffness of concrete

Results similar to those shown in Figs. 7 and 8 were also observed when SS400 and FC250 were used for the metal specimen. These results were used to determine the stiffness between the upper and lower specimens for all the specimen sets. Figure 9 shows a comparison of the normal stiffnesses $K_{n m m}$ and $K_{n m c}$, and Fig. 10 shows a comparison of the tangential stiffnesses between the upper and lower specimens. In both figures, the stiffness of the metal-concrete specimen set is observed to be lower than those of the metal-metal specimen sets. Moreover, the stiffness is almost the same when different materials were used for the upper and middle specimens of the metal-concrete specimen set. This indicates that the stiffness of a metal-concrete interface is primarily determined by concrete.

Figures 11 and 12 show the values of $\delta k_{n c}$ and $\delta k_{t c}$, respectively, for the metal-concrete specimens. As is the case with the metals listed in Table 2, the values of $\delta k_{n c}$ is about 10 times those of $\delta k_{t c}$, although the respective values are smaller than those of the metals. The values of $\delta k_{n c}$ are in the range of $1 / 67-1 / 23$ of those of the metals, while those of $\delta k_{t c}$ are in the range of 1/79-1/68. The large difference between the observed stiffness of concrete and those of metals can be partly attributed to the fact that the values of $\delta k_{n c}$ and $\delta k_{t c}$ obtained from this experiment were affected by the difference 
between the bulk stiffness of concrete and that of the interfacing metal. As a result, $\delta k_{n c}$ and $\delta k_{t c}$ are slightly higher when the lower specimen is FC250, since its elastic modulus is lower than those of S50C and SS400.

\section{Experimental verification of the stiffness model}

\subsection{Model of a machine tool bed used for verification}

An experiment is performed to verify the stiffness model proposed above. The natural frequency and vibration mode shape of a small model of a machine tool bed are estimated and compared with experimental results.

Figure 13 shows the machine tool bed model, a block of FC250, that was used for the experiment. The mass of the block is about $23 \mathrm{~kg}$. The block is freely mounted on the concrete floor atop three cylindrical supports made of SS400. The supports are positioned as illustrated in Fig. 14. To simplify the calculation of the normal preload on each, the supports are positioned symmetrically about the center of gravity of the machine tool model.

All the interfaces of the model and floor are ground and cleaned with a cleaning fluid. The surface roughnesses of the interfaces were measured by a contact type surface roughness measuring machine (Mitutoyo). In particular, the surface roughness of the floor was measured by a portable type surface roughness measuring machine. The surface roughness of the bed was estimated from the measurement with a plate of FC250 ground similarly to the bed because the bed is too large for the measuring machine. The surface roughnesses of the support and bed are $3.9 \mu \mathrm{mRz}$ and $9.6 \mu \mathrm{mRz}$, respectively. The surface roughness of the floor ranges from $46 \mu \mathrm{mRz}$ to $99 \mu \mathrm{mRz}$ depending on the measurement position.

Using the stiffness model described in Section 2.1, the stiffness of each support is calculated from the five components shown in Fig. 15. The contact stiffness is

Measurement point in the

experimental modal analysis

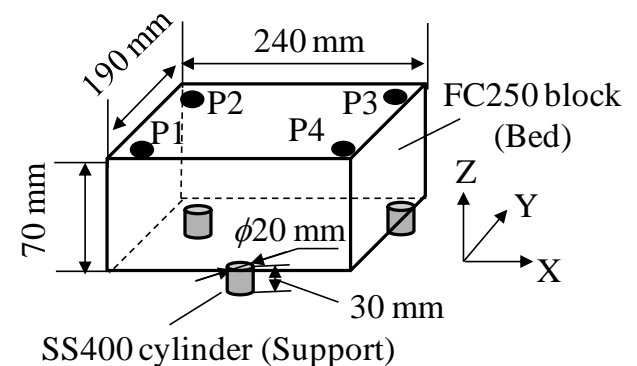

Fig. 13 Model of a machine tool bed

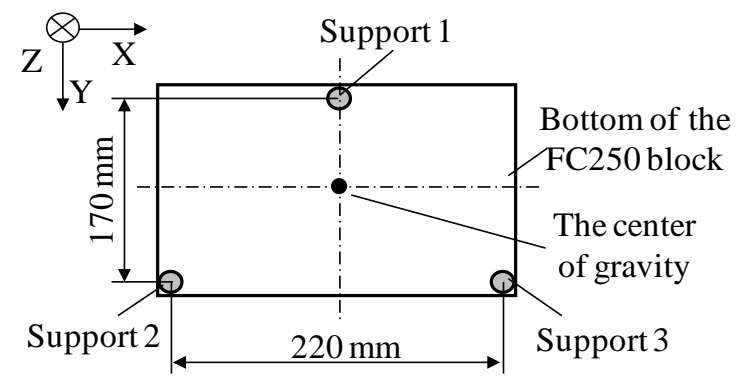

Fig. 14 Position of supports

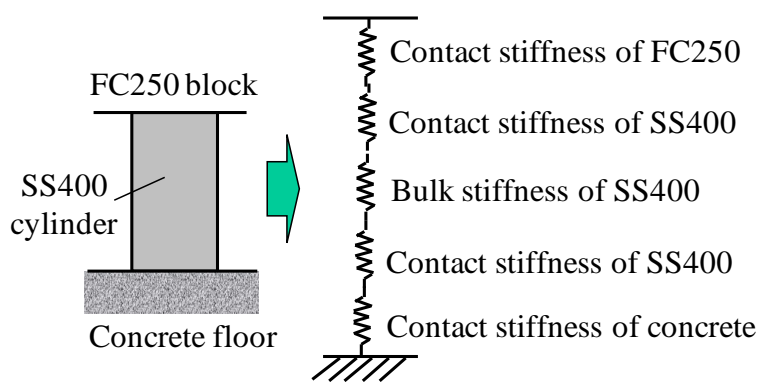

Fig. 15 Stiffness model of supports 
Table 3 Estimated stiffness of supports

\begin{tabular}{ll|c|c|c|c}
\hline & \multicolumn{2}{|c|}{ Normal direction } & \multicolumn{2}{c}{ Tangential direction } \\
\cline { 3 - 6 } & Support 1 & $\begin{array}{c}\text { Supports } \\
2 \text { and 3 }\end{array}$ & Support 1 & $\begin{array}{c}\text { Supports } \\
2 \text { and 3 }\end{array}$ \\
\hline Contact stiffness of FC250 N/mm & $6.3 \times 10^{5}$ & $3.1 \times 10^{5}$ & $1.3 \times 10^{5}$ & $6.6 \times 10^{4}$ \\
\hline Contact stiffness of SS400 N/mm & $1.1 \times 10^{6}$ & $5.6 \times 10^{5}$ & $1.0 \times 10^{5}$ & $5.0 \times 10^{4}$ \\
\hline Bulk stiffness of SS400 N/mm & $2.2 \times 10^{6}$ & $2.2 \times 10^{6}$ & $1.8 \times 10^{5}$ & $1.8 \times 10^{5}$ \\
\hline Contact stiffness of SS400 N/mm & $3.6 \times 10^{6}$ & $1.8 \times 10^{6}$ & $3.2 \times 10^{5}$ & $1.6 \times 10^{5}$ \\
\hline Contact stiffness of concrete N/mm & $6.6 \times 10^{4}$ & $3.3 \times 10^{4}$ & $4.3 \times 10^{3}$ & $2.2 \times 10^{3}$ \\
\hline Total stiffness of the support N/mm & $5.5 \times 10^{4}$ & $2.8 \times 10^{4}$ & $3.9 \times 10^{3}$ & $2.0 \times 10^{3}$ \\
\hline
\end{tabular}

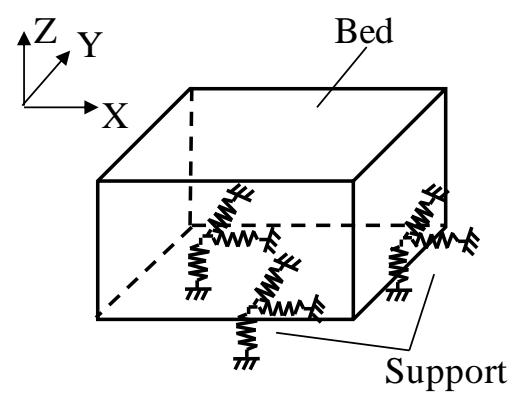

Fig. 16 Rigid body model used in the estimation

calculated from the normal preload and the unit contact stiffness. The unit contact stiffness given in Section 3 is used. The bulk stiffness is determined using analytical formulas of the axial stiffness and bending stiffness of a cylinder. Table 3 lists the calculated values. For both normal and tangential directions, the contact stiffness of concrete is found to be less than $1 / 10$ of the others and primarily determines the overall stiffness of the supports.

\subsection{Method of vibration mode shape analysis by estimation and experiment}

The rigid body model is used to estimate the natural frequency and vibration mode shape. Figure 16 shows the developed model. The block is approximated by a rigid cuboid with six degrees of freedom. The block is coupled to the inertial system by three $3 \mathrm{D}$ stiffnesses corresponding to the supports. The calculation is conducted with a software for rigid body simulation, Axis Construction Kit [16].

An impulse hammer (PCB Piezotronics) is used to conduct an impact test to experimentally analyze the vibration mode shape. The block is excited at its center in the $\mathrm{Y}$ and $\mathrm{Z}$ directions. To obtain a 3D vibration mode shape, a 3D accelerometer (PCB Piezotronics) is used to measure the acceleration at four corners, P1-P4, shown in Fig. 13. The frequency response between the excitation force and acceleration is computed with a portable FFT-analyzer (Ono Sokki). Then, the frequency response between the excitation force and displacement is obtained by integration. The sensitivities of the impulse hammer and the accelerometer are $2.3 \mathrm{mV} / \mathrm{N}$ and $50 \mathrm{mV} / \mathrm{m} / \mathrm{s}^{2}$, respectively. The measurement frequency range is set to $500 \mathrm{~Hz}$, and the number of sample points is 2048. The number of averaging is five. 


\subsection{Experimental result}

The measured frequency responses between the excitation force and displacement are shown in Figs. 17 and 18. In Fig. 17 which shows the result in the Y direction, three resonance peaks are observed at $60 \mathrm{~Hz}, 83 \mathrm{~Hz}$, and $117 \mathrm{~Hz}$. In Fig. 18 which shows the result in the $\mathrm{Z}$ direction, two resonance peaks are seen at $312 \mathrm{~Hz}$ and $382 \mathrm{~Hz}$. These five resonance peaks correspond to the first five vibration modes of the model.

\subsection{Comparison of experimentally measured and estimated vibrations}

Table 4 presents a comparison of the natural frequency and vibration mode shape of the first five vibration modes. In the table, the natural frequencies estimated considering only the bulk stiffness of the support are also shown for comparison. Although the

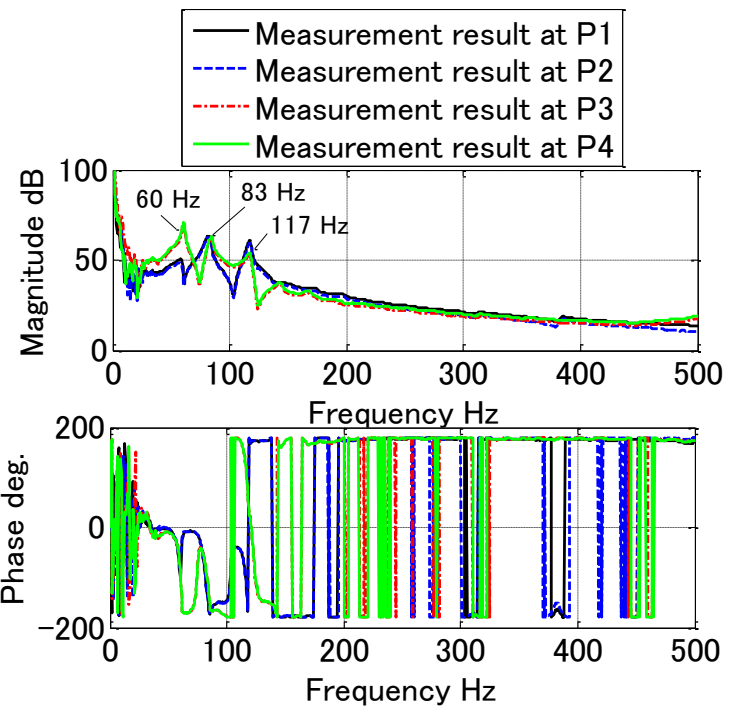

Fig. 17 Frequency response between the excitation force in the $Y$ direction and the displacement in the $\mathrm{Y}$ direction
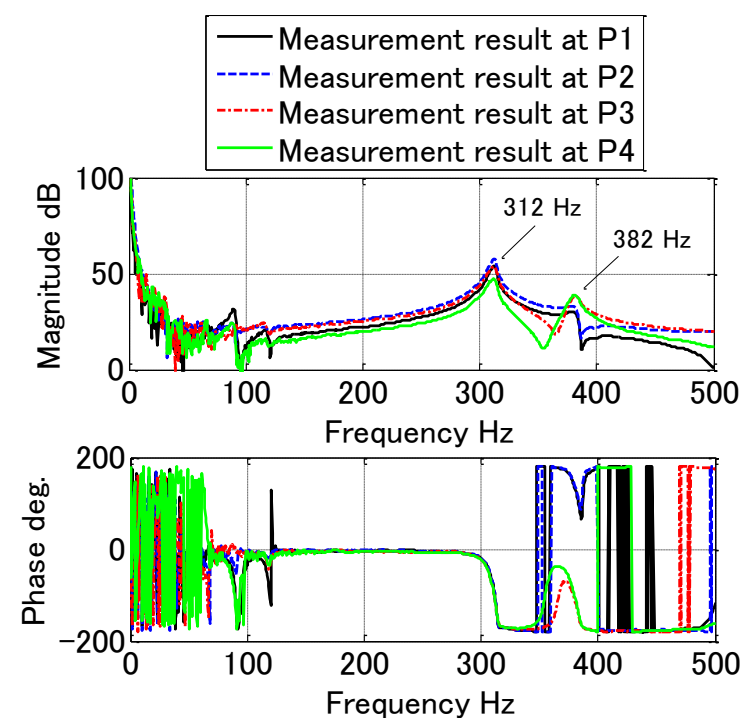

Fig. 18 Frequency response between the excitation force in the $\mathrm{Z}$ direction and the displacement in the $\mathrm{Z}$ direction

Table 4 Comparison of natural frequency and vibration mode shape

\begin{tabular}{|c|c|c|c|c|c|}
\hline \multirow{2}{*}{$\begin{array}{l}\text { Mode } \\
\text { No. }\end{array}$} & \multicolumn{2}{|c|}{$\begin{array}{l}\text { Estimation with the proposed } \\
\text { model }\end{array}$} & \multicolumn{2}{|c|}{ Experiment } & \multirow{2}{*}{$\begin{array}{c}\text { Estimation } \\
\text { considering only } \\
\text { the bulk stiffness } \\
\begin{array}{c}\text { Natural } \\
\text { frequency } \mathrm{Hz}\end{array}\end{array}$} \\
\hline & $\begin{array}{c}\text { Natural } \\
\text { frequency } \mathrm{Hz}\end{array}$ & $\begin{array}{l}\text { Mode shape } \\
\text { description }\end{array}$ & $\begin{array}{c}\text { Natural } \\
\text { frequency } \\
\mathrm{Hz} \\
\end{array}$ & $\begin{array}{l}\text { Mode shape } \\
\text { description }\end{array}$ & \\
\hline Mode 1 & 93 & $\begin{array}{l}\text { Translation in } \\
\text { the X direction }\end{array}$ & 60 & $\begin{array}{l}\text { Translation in the } \\
\text { diagonal direction } \\
\text { in the XY plane }\end{array}$ & 729 \\
\hline Mode 2 & 93 & $\begin{array}{l}\text { Translation in } \\
\text { the Y direction }\end{array}$ & 83 & $\begin{array}{l}\text { Translation in the } \\
\text { diagonal direction } \\
\text { in the XY plane }\end{array}$ & 765 \\
\hline Mode 3 & 122 & $\begin{array}{l}\text { Rotation around } \\
\text { the } \mathrm{Z} \text { direction }\end{array}$ & 117 & $\begin{array}{l}\text { Rotation around the } \\
\mathrm{Z} \text { direction }\end{array}$ & 1104 \\
\hline Mode 4 & 350 & $\begin{array}{l}\text { Translation in } \\
\text { the } \mathrm{Z} \text { direction }\end{array}$ & 312 & $\begin{array}{c}\text { Translation in the } \mathrm{Z} \\
\text { direction }\end{array}$ & 2444 \\
\hline Mode 5 & 381 & $\begin{array}{l}\text { Rotation around } \\
\text { the } \mathrm{Y} \text { direction }\end{array}$ & 382 & $\begin{array}{l}\text { Rotation around the } \\
\text { Y direction }\end{array}$ & 3377 \\
\hline
\end{tabular}


natural frequency considering only the bulk stiffness is almost 10 times that of the experimental value, the estimation with the proposed model is comparable to the experiment.

The difference in the vibration mode shapes of modes 1 and 2 can be attributed to two factors. The first is that the normal load distribution was uneven due to the flatness of the concrete floor, which caused the normal preload on Support 2 to be less than those on supports 1 and 3. In order to verify the effect of the normal load distribution, the support should have a function to measure the normal load. The second is that the concrete of the specimen of Section 3 was not the same as that of the floor of Section 4. In the light of this, and considering that the contact properties of the floor differ from place to place, it would be necessary to consider the unit contact stiffness of the floor of the particular workshop in which a machine tool bed is to be installed.

The observations of the experiment show that the contact stiffness of the supports significantly determined the vibration of the block. The normal preload of the experiment was less than what is usually encountered in actual cases because the mass of the block model was less than that of real machine tool beds. Consequently, the influence of the contact stiffness in the experiment was greater than what is obtained in actual cases. However, even if the mass of the experimental block had been 100 times that of what was used, the contact stiffness of the concrete floor could not be ignored, since it would still be equal to the bulk stiffness (see Table 3). On the basis of the results of this study, it is proposed that the contact stiffness between the supports of a machine tool bed and the concrete floor primarily determines the vibration properties of the machine.

\section{Conclusions}

A 3D stiffness model of a machine tool support was proposed in this study using contact stiffness. The stiffness in each direction was assumed to be determined by the contact stiffness at the interfaces and the bulk stiffness between the supports and the floor. The contact stiffness model proposed by Shimizu et al. was expanded to determine the contact stiffness in the normal and tangential directions of an interface. In the proposed model, the contact stiffness is obtained by multiplying the unit contact stiffness by the real contact area. The contact stiffness of concrete was experimentally investigated to estimate the stiffness between machine tool supports and the floor, and it was observed to be the primary determinant of the stiffness of interfaces between metal and concrete. Moreover, the unit contact stiffness of concrete was discovered to be less than $1 / 10$ of those of the metals that were used for the study. The natural frequency and vibration mode shape of a model machine tool bed were also experimentally measured and used to verify the proposed stiffness model. The comparison of the results obtained from the two procedures showed that the natural frequency and vibration mode shape of a machine tool bed can be predicted using the proposed stiffness model.

\section{Acknowledgements}

This work was supported by Mazak foundation and KAKENHI (24760104). 


\section{References}

[1] Eugene I.Rivin: Vibration isolation of precision equipment, Precision Engineering 1995;17:41.

[2] C.F.J.Geerts, G.H.Veldhuizent: Precision copying machine for variable curvature surfaces, Precision Engineering 1984;6:9.

[3] D.C.Thompson, J.L.Chrislock, L.E.Newton: T Development of an inexpensive, high accuracy diamond turning machine, Precision Engineering, 1982;4:73.

[4] Tomonori Kato, Kenji Kawashima, Tatsuya Funaki, Kotaro Tadano, Toshiharu Kagawa: A new, high precision, quick response pressure regulator for active control of pneumatic vibration isolation tables, Precision Engineering, 2010;34:43.

[5] T.Hoshi: Chatter Vibration in Machining -Analysis and Countermeasure-, Kogyo Chosakai Publishing Co., Ltd., Tokyo, 1977, pp.210-227.(in Japanese)

[6] K.Yoshida, H.Shimura, H.Yahagi, J.Yoshioka: Effects of mounting elements of surface grinding machines upon their relative receptances between grinding wheel and work table, Journal of mechanical working technology 1988;17:377.

[7] R.D.Mindlin: Compliances of elastic bodies in contact, Journal of applied mechanics 1949;16:259.

[8] J.A.Greenwood, J.B.P.Williamson: Contact of nominally flat surfaces, Proceedings of royal society London 1966; A295:300.

[9] Hany.A.Sherif, S.S.Kossa: Relationship between normal and tangential contact stiffness of nominally flat surfaces, Wear 1991;151:49.

[10] Masatoshi Hashimoto, Etsuo Marui, Shinobu Kato: Estimation of contact stiffness at interfaces in machine structures by a beam model on an elastic foundation, Tribology international 1994;27:423.

[11] M.Gonzalez-Valadez, A.Baltazar, R.S.Dwyer-Joyce: Study of interfacial stiffness ratio of a rough surface in contact using a spring model, Wear 2010;268:373.

[12] R.H.Thornley, R.Connolly, M.M.Barash, F.Koeningsberger: The effect of surface topography upon the static stiffness of machine tool joints, International journal of Machine tool design and research 1965;5:57.

[13] Shinji Shimizu, Kyoko Nakamura, Haruhisa Sakamoto: Quantitative Measurement method of contact stiffness of the joint with different material combination, Journal of advanced mechanical design systems and manufacturing 2010;4:1044.

[14] F.P.Bowden, and D.Tabor: The Friction and Lubrication of Solids, Oxford , 1954, (Translated by N.Soda, Maruzen Company Ltd., Tokyo, 1961), pp.9-17.

[15] D.Kono, T.Inagaki, A.Matsubara, and I.Yamaji: Measurement of contact stiffness for stiffness estimation of machine tool supports, Key Engineering Materials 2012; 523-524:457, Proceedings of the 14th International Conference on Precision Engineering (ICPE 2012).

[16] Th. Lorenzer, S.Weikert, S. Bossoni and K. Wegener: Modeling and evaluation tool for supporting decisions on the design of reconfigurable machine tools, Journal of Manufacturing Systems 2007;26:167. 


\section{List of Figure Captions}

Fig. 1 Machine tool support and its model

(a) Examples of machine tool support

(b) 3D stiffness model of the support

(c) 1D stiffness model involving bulk and contact stiffness

Fig. 2 Model of contact stiffness
(a) Contact stiffness in the support
(b) Unit contact stiffness model at the interface

Fig. 3 Specimen set used in the measurement

Fig. 4 Material combinations of the specimen set
(a) Metal-concrete specimen set
(b) Metal-metal specimen set

Fig, 5 Schematic of measurement in the normal direction

Fig, 6 Schematic of measurement setup

(a) Measurement in the normal direction

(b) Measurement in the tangential direction

Fig. 7 Relationship between normal displacement and load for the metal-concrete specimen set. The material of the metal specimen is S50C.

Fig. 8 Relationship between tangential displacement and load for the metal-concrete specimen set. The material of the metal specimen is S50C.

Fig. 9 Comparison of normal stiffness between the upper and lower specimens

Fig. 10 Comparison of tangential stiffness between the upper and lower specimens

Fig. 11 Unit normal contact stiffness of concrete

Fig. 12 Unit tangential contact stiffness of concrete

Fig. 13 Model of a machine tool bed

Fig. 14 Position of supports

Fig. 15 Stiffness model of supports

Fig. 16 Rigid body model used in the estimation

Fig. 17 Frequency response between the excitation force in the Y direction and the displacement in the $\mathrm{Y}$ direction

Fig. 18 Frequency response between the excitation force in the $\mathrm{Z}$ direction and the displacement in the $\mathrm{Z}$ direction 
Table 1 Specifications of measuring instruments

\begin{tabular}{ccc}
\hline Force sensor & Measuring range & $\pm 5 \mathrm{kN}$ \\
& Accuracy & $\pm 1 \%$ \\
\hline \multirow{2}{*}{ Load cell } & Measuring range & $\pm 10 \mathrm{kN}$ \\
& Accuracy & $\pm 0.02 \%$ \\
\hline Capacitive & Measuring range & $\pm 250 \mu \mathrm{m}$ \\
displacement & Accuracy & $\pm 1 \%$ \\
\hline
\end{tabular}


Table 2 Specifications of specimens

\begin{tabular}{c|c|c|c|c}
\hline Material & S50C & SS400 & FC250 & Concrete \\
\hline Longitudinal elastic modulus GPa & 205 & 206 & 127 & $25-40$ \\
\hline Measured Vickers hardness $\mathrm{kgf} / \mathrm{mm}^{2}$ & 230 & 180 & 230 & $\begin{array}{c}56 \text { (mortar) } \\
1470 \text { (gravel) }\end{array}$ \\
\hline Measured surface roughness $\mathrm{Rz} \mu \mathrm{m}$ & 4.0 & 1.1 & 1.5 & 3.6 \\
\hline Unit normal contact stiffness $\delta k_{n} \mathrm{~N} / \mathrm{mm} / \mathrm{mm}^{2}$ & $\begin{array}{c}1.4 \times \\
10^{7}\end{array}$ & $\begin{array}{c}1.8 \times \\
10^{7}\end{array}$ & $\begin{array}{c}1.0 \times \\
10^{7}\end{array}$ & Not measured \\
\hline Unit tangential contact stiffness $\delta k_{t} \mathrm{~N} / \mathrm{mm} / \mathrm{mm}^{2}$ & $\begin{array}{c}1.6 \times \\
10^{6}\end{array}$ & $\begin{array}{c}1.6 \times \\
10^{6}\end{array}$ & $\begin{array}{c}2.0 \times \\
10^{6}\end{array}$ & Not measured \\
\hline
\end{tabular}


Table 3 Estimated stiffness of supports

\begin{tabular}{ll|c|c|c|c}
\hline \multirow{2}{*}{} & \multicolumn{2}{|c|}{ Normal direction } & \multicolumn{2}{c}{ Tangential direction } \\
\cline { 3 - 6 } & Support 1 & $\begin{array}{c}\text { Supports } \\
2 \text { and 3 }\end{array}$ & Support 1 & $\begin{array}{c}\text { Supports } \\
2 \text { and 3 }\end{array}$ \\
\hline Contact stiffness of FC250 N/mm & $6.3 \times 10^{5}$ & $3.1 \times 10^{5}$ & $1.3 \times 10^{5}$ & $6.6 \times 10^{4}$ \\
\hline Contact stiffness of SS400 N/mm & $1.1 \times 10^{6}$ & $5.6 \times 10^{5}$ & $1.0 \times 10^{5}$ & $5.0 \times 10^{4}$ \\
\hline Bulk stiffness of SS400 N/mm & $2.2 \times 10^{6}$ & $2.2 \times 10^{6}$ & $1.8 \times 10^{5}$ & $1.8 \times 10^{5}$ \\
\hline Contact stiffness of SS400 N/mm & $3.6 \times 10^{6}$ & $1.8 \times 10^{6}$ & $3.2 \times 10^{5}$ & $1.6 \times 10^{5}$ \\
\hline Contact stiffness of concrete $\quad \mathrm{N} / \mathrm{mm}$ & $6.6 \times 10^{4}$ & $3.3 \times 10^{4}$ & $4.3 \times 10^{3}$ & $2.2 \times 10^{3}$ \\
\hline Total stiffness of the support $\mathrm{N} / \mathrm{mm}$ & $5.5 \times 10^{4}$ & $2.8 \times 10^{4}$ & $3.9 \times 10^{3}$ & $2.0 \times 10^{3}$ \\
\hline
\end{tabular}


Table 4 Comparison of natural frequency and vibration mode shape

\begin{tabular}{|c|c|c|c|c|c|}
\hline \multirow{2}{*}{$\begin{array}{l}\text { Mode } \\
\text { No. }\end{array}$} & \multicolumn{2}{|c|}{$\begin{array}{l}\text { Estimation with the proposed } \\
\text { model }\end{array}$} & \multicolumn{2}{|c|}{ Experiment } & \multirow{2}{*}{$\begin{array}{c}\text { Estimation } \\
\text { considering only } \\
\text { the bulk stiffness } \\
\begin{array}{c}\text { Natural } \\
\text { frequency } \mathrm{Hz}\end{array}\end{array}$} \\
\hline & $\begin{array}{l}\text { Natural } \\
\text { frequency } \mathrm{Hz}\end{array}$ & $\begin{array}{l}\text { Mode shape } \\
\text { description }\end{array}$ & $\begin{array}{c}\text { Natural } \\
\text { frequency } \\
\mathrm{Hz}\end{array}$ & $\begin{array}{l}\text { Mode shape } \\
\text { description }\end{array}$ & \\
\hline Mode 1 & 93 & $\begin{array}{l}\text { Translation in } \\
\text { the } \mathrm{X} \text { direction }\end{array}$ & 60 & $\begin{array}{l}\text { Translation in the } \\
\text { diagonal direction } \\
\text { in the XY plane }\end{array}$ & 729 \\
\hline Mode 2 & 93 & $\begin{array}{l}\text { Translation in } \\
\text { the Y direction }\end{array}$ & 83 & $\begin{array}{l}\text { Translation in the } \\
\text { diagonal direction } \\
\text { in the XY plane }\end{array}$ & 765 \\
\hline Mode 3 & 122 & $\begin{array}{l}\text { Rotation around } \\
\text { the } \mathrm{Z} \text { direction }\end{array}$ & 117 & $\begin{array}{l}\text { Rotation around the } \\
\mathrm{Z} \text { direction }\end{array}$ & 1104 \\
\hline Mode 4 & 350 & $\begin{array}{l}\text { Translation in } \\
\text { the } \mathrm{Z} \text { direction }\end{array}$ & 312 & $\begin{array}{c}\text { Translation in the } \mathrm{Z} \\
\text { direction }\end{array}$ & 2444 \\
\hline Mode 5 & 381 & $\begin{array}{l}\text { Rotation around } \\
\text { the Y direction }\end{array}$ & 382 & $\begin{array}{l}\text { Rotation around the } \\
\text { Y direction }\end{array}$ & 3377 \\
\hline
\end{tabular}




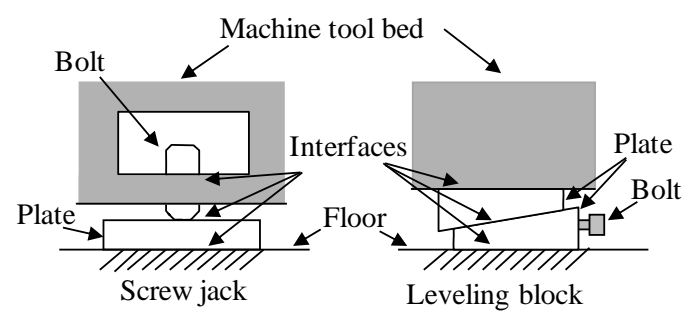

(a) Examples of machine tool support

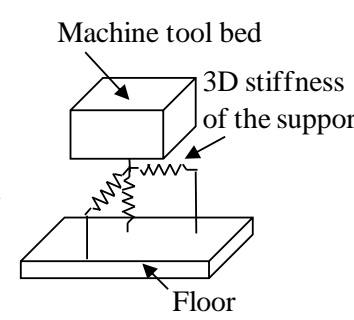

(b) 3D stiffness model of the support
Machine tool bed

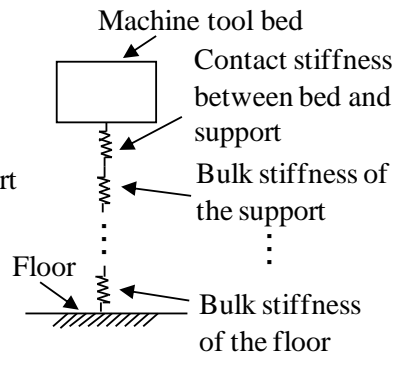

(c) 1D stiffness model involving bulk and contact stiffness

Fig. 1 Machine tool support and its model 


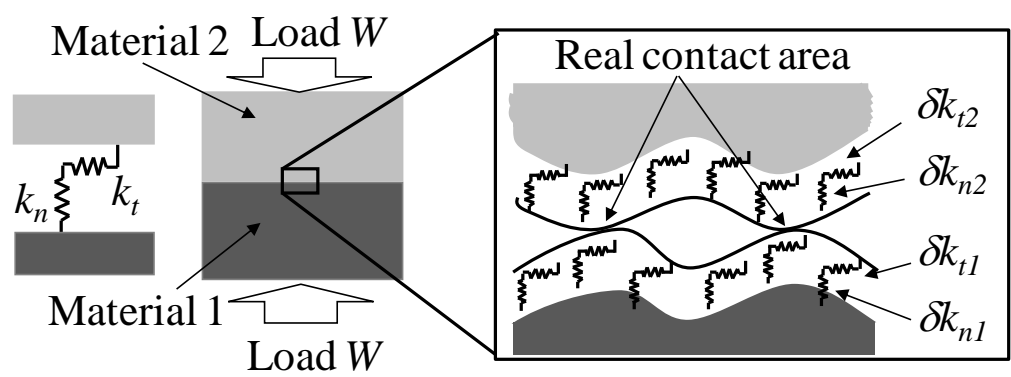

(a) Contact stiffness in the support

(b) Unit contact stiffness model at the interface

Fig. 2 Model of contact stiffness 


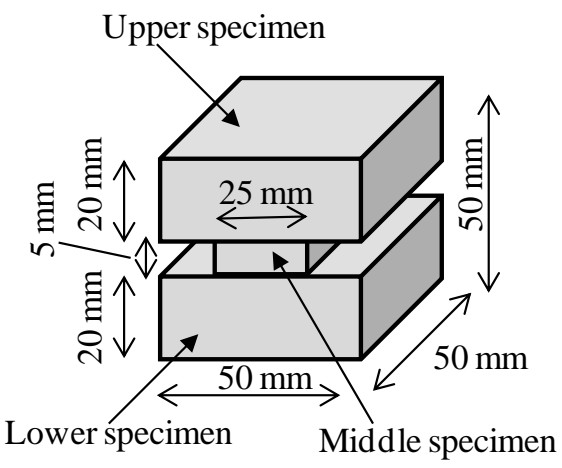

Fig. 3 Specimen set used in the measurement 


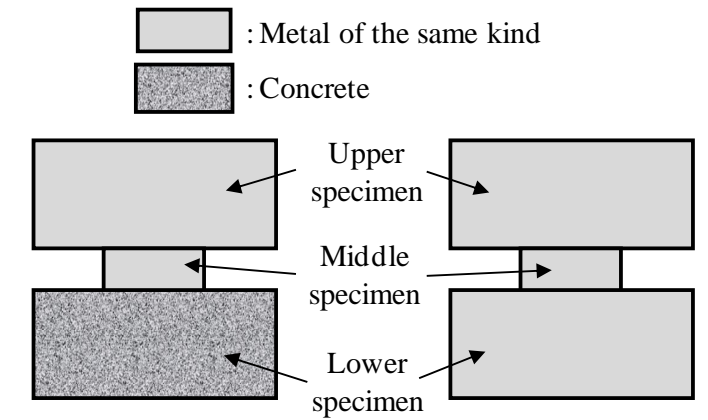

(a) Metal-concrete

(b) Metal-metal specimen set specimen set

Fig. 4 Material combinations of the specimen set 


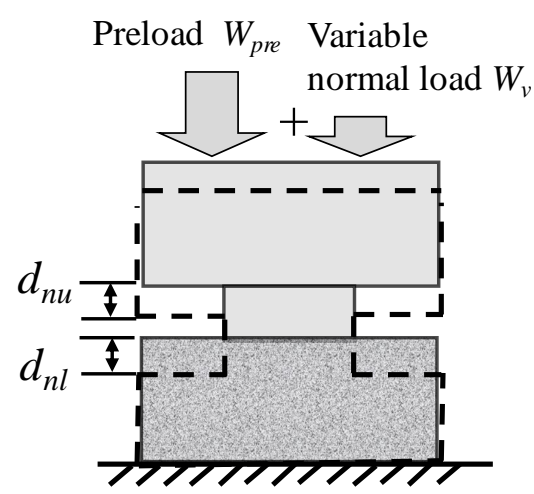

Fig. 5 Schematic of measurement in the normal direction 


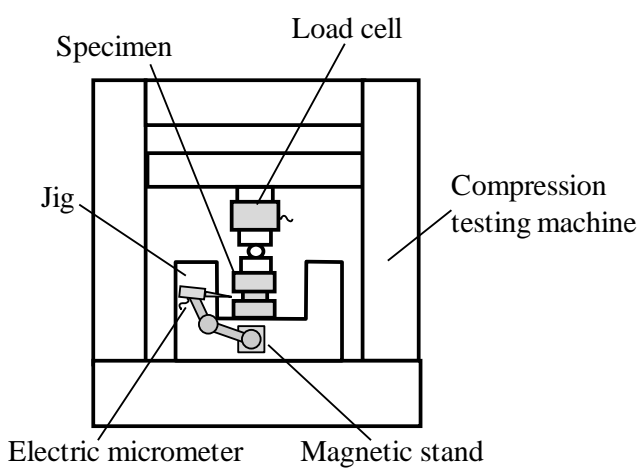

(a) Measurement in the normal direction

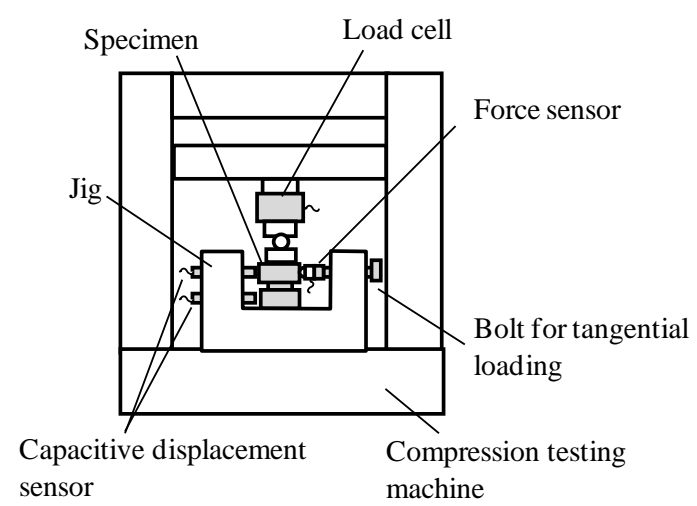

(b) Measurement in the tangential direction

Fig. 6 Schematic of measurement setup 


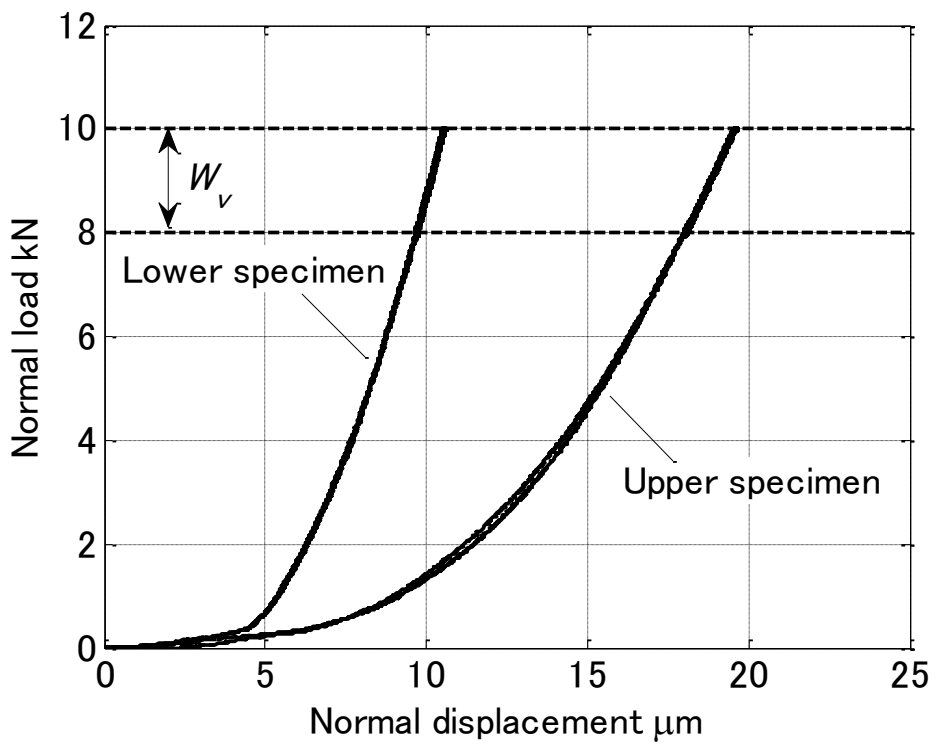

Fig.7 Relationship between normal displacement and load for the metal-concrete specimen set. The material of the metal specimen is S50C. 


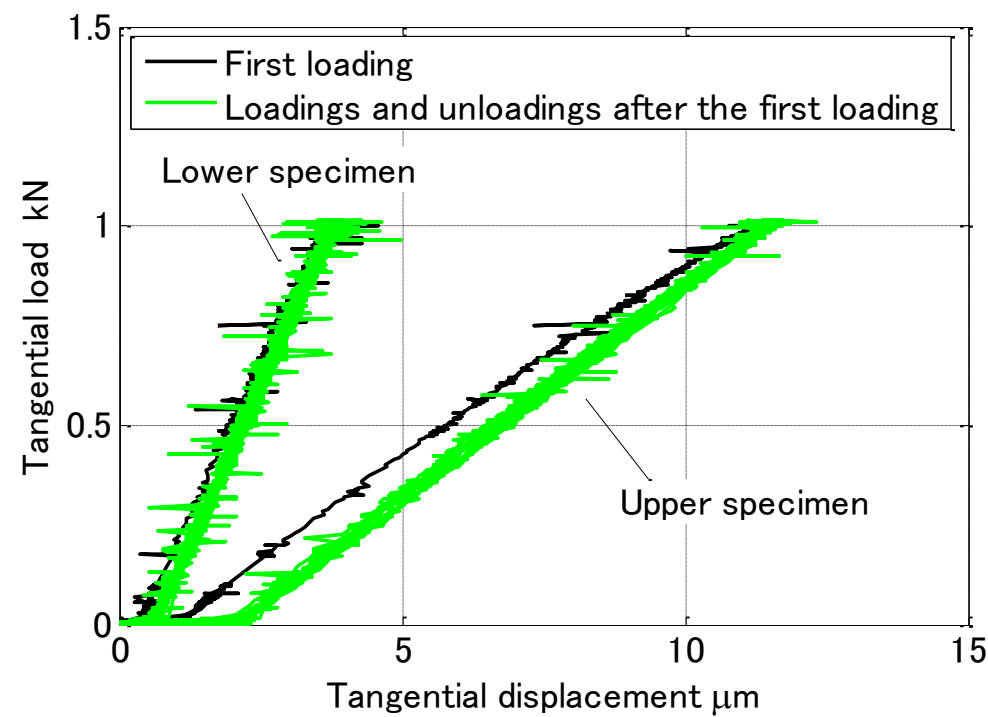

Fig.8 Relationship between tangential displacement and load for the metal-concrete specimen set. The material of the metal specimen is S50C. 


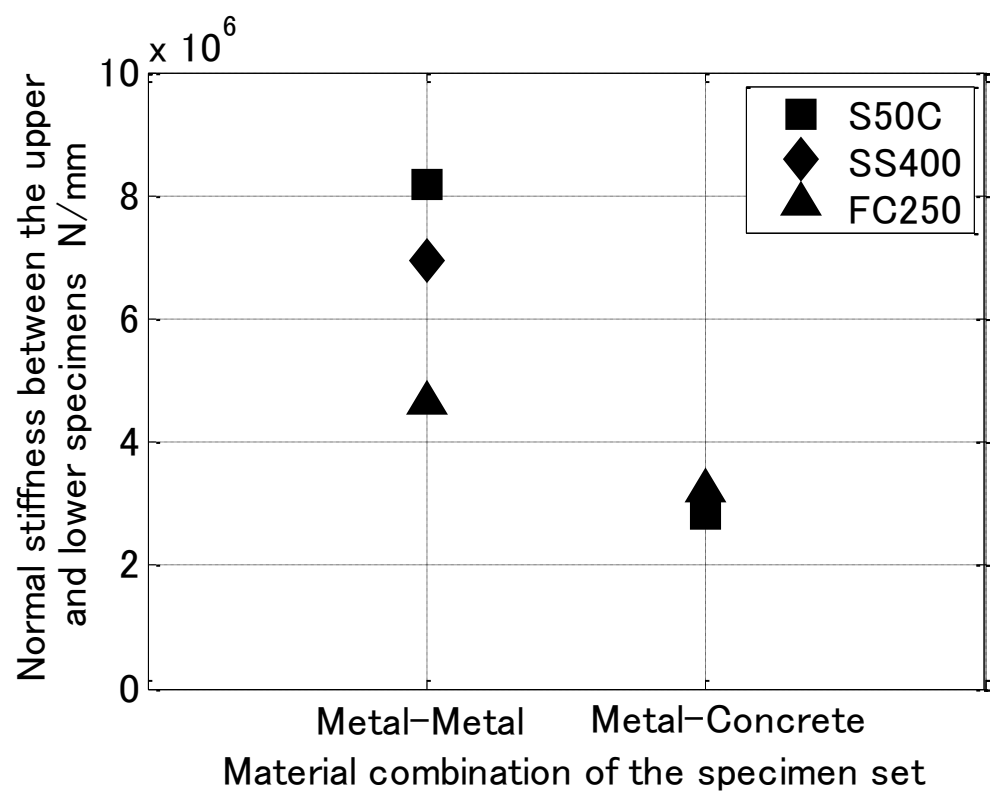

Fig. 9 Comparison of normal stiffness between the upper and lower specimens 


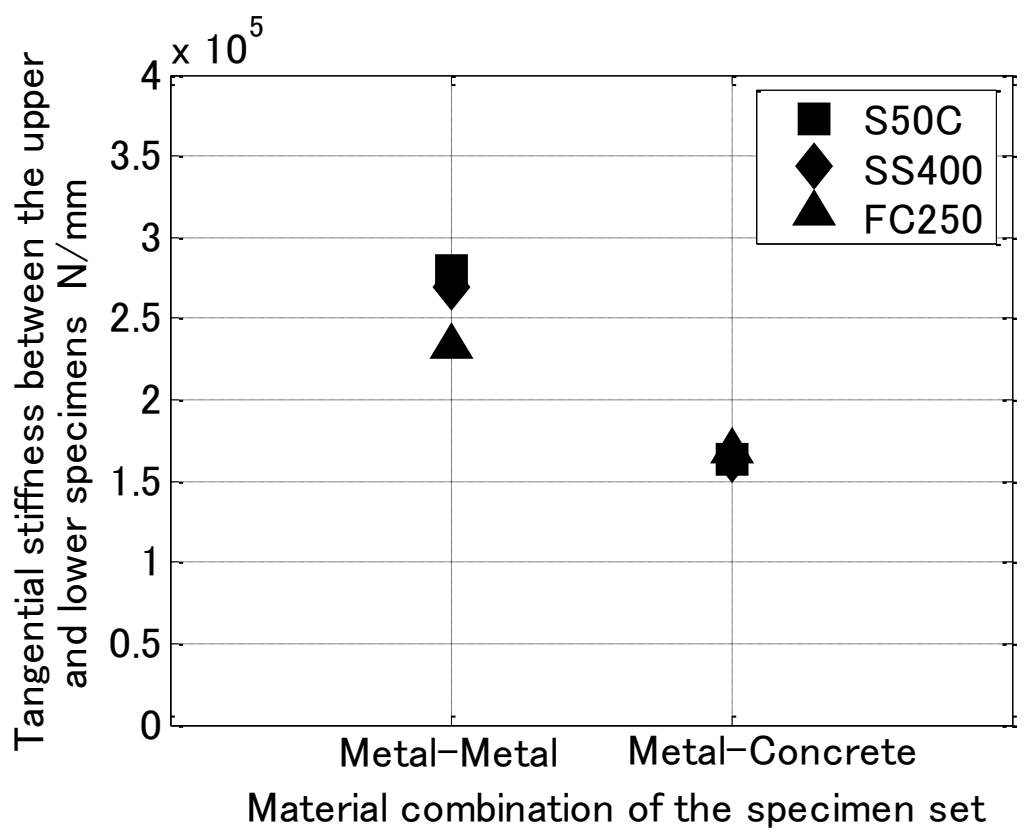

Fig. 10 Comparison of tangential stiffness between the upper and lower specimens 


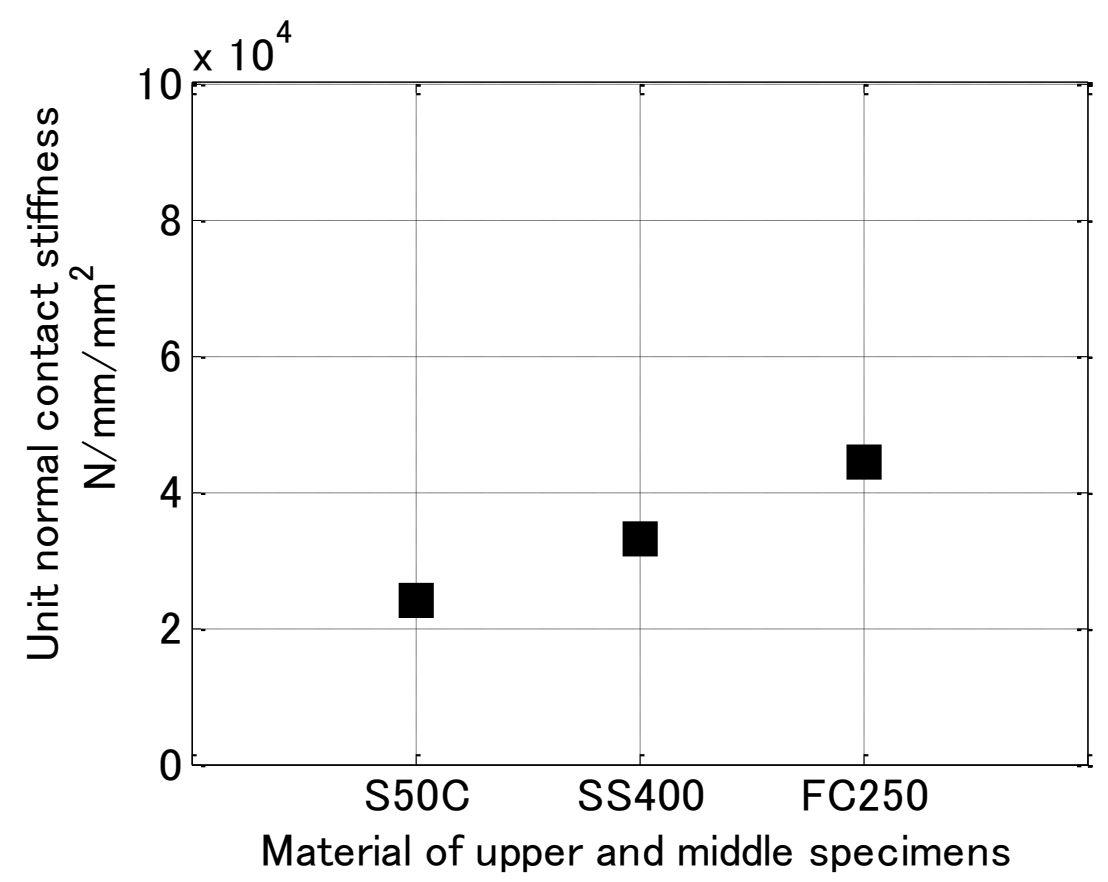

Fig. 11 Unit normal contact stiffness of concrete 


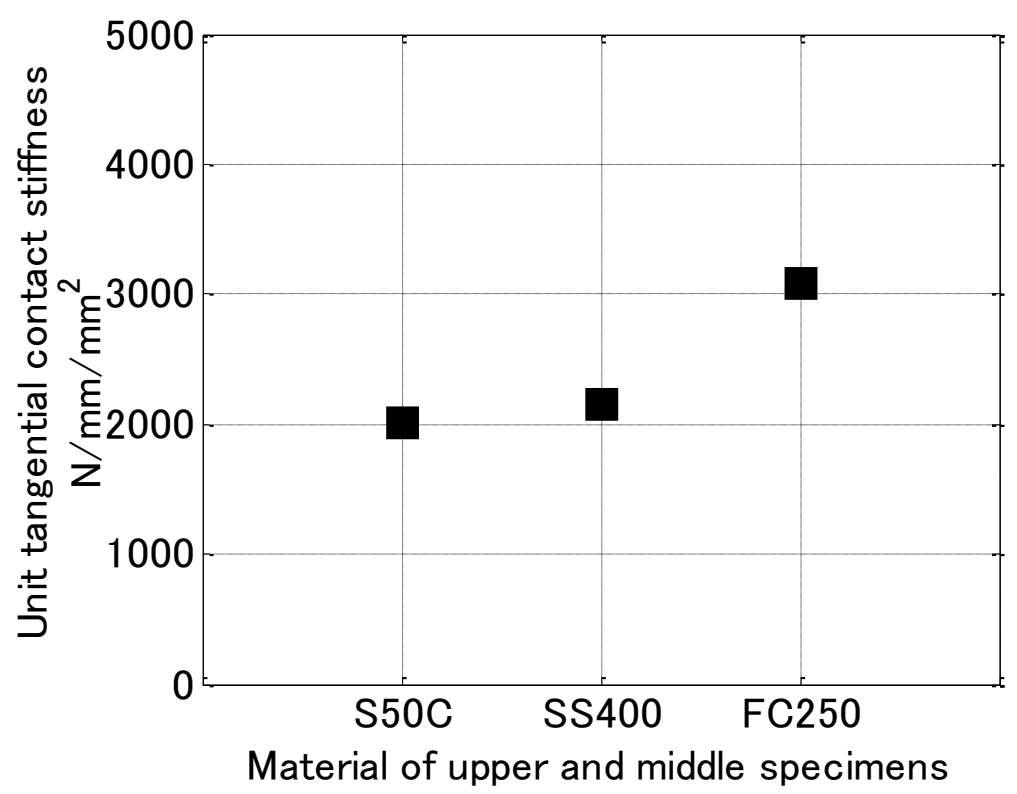

Fig. 12 Unit tangential contact stiffness of concrete 
- Measurement point in the experimental modal analysis

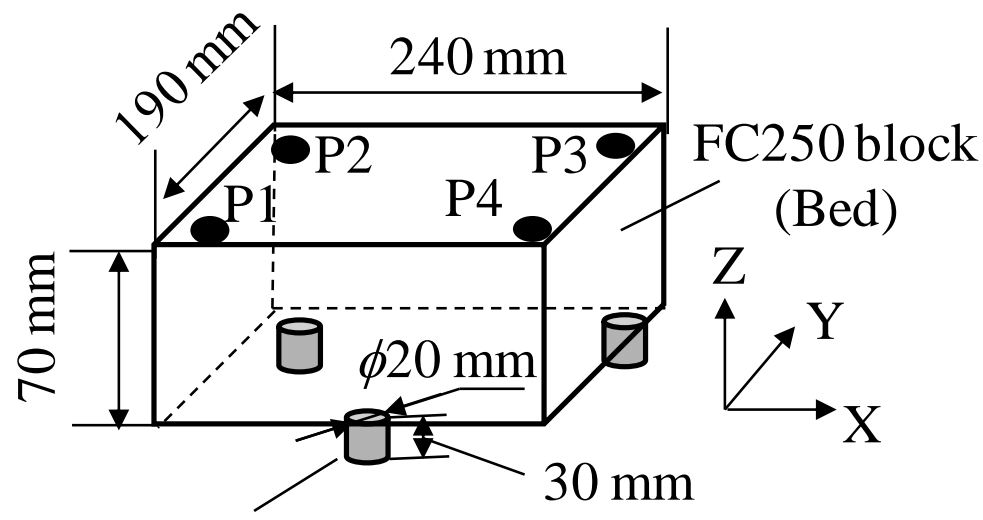

SS400 cylinder (Support)

Fig. 13 Model of a machine tool bed 


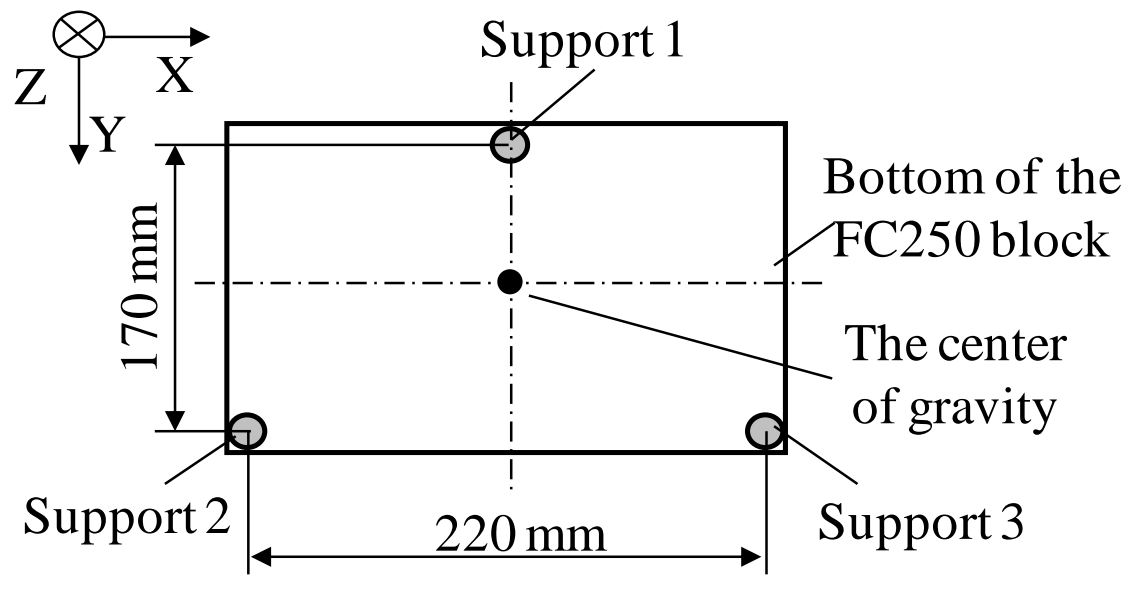

Fig. 14 Position of supports 


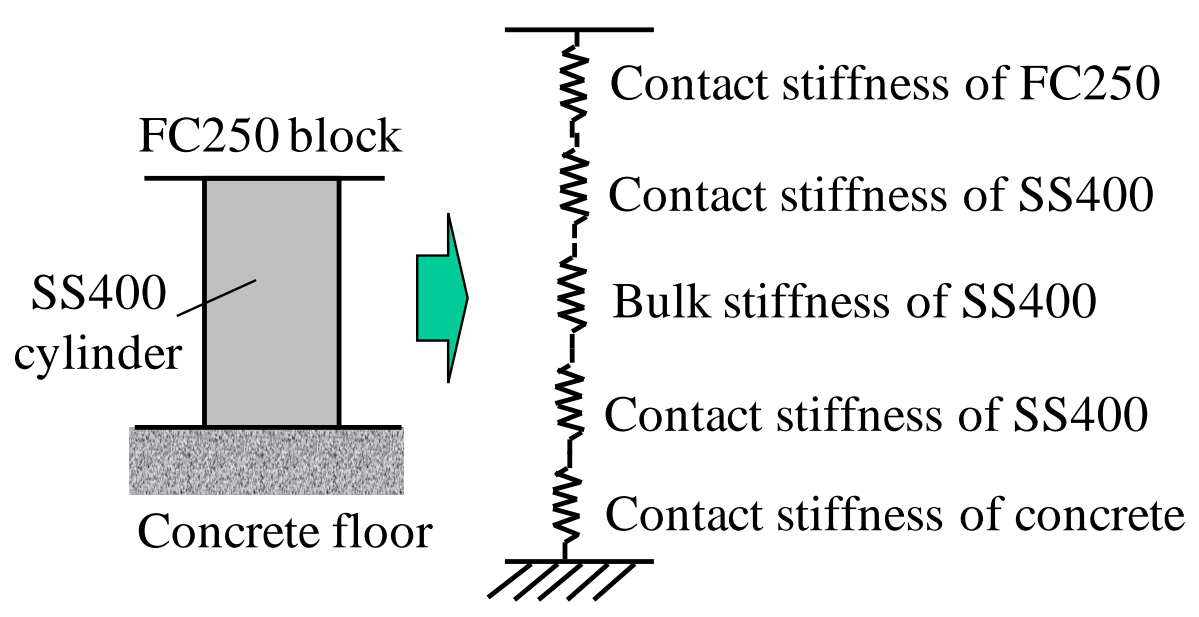

Fig. 15 Stiffness model of supports 


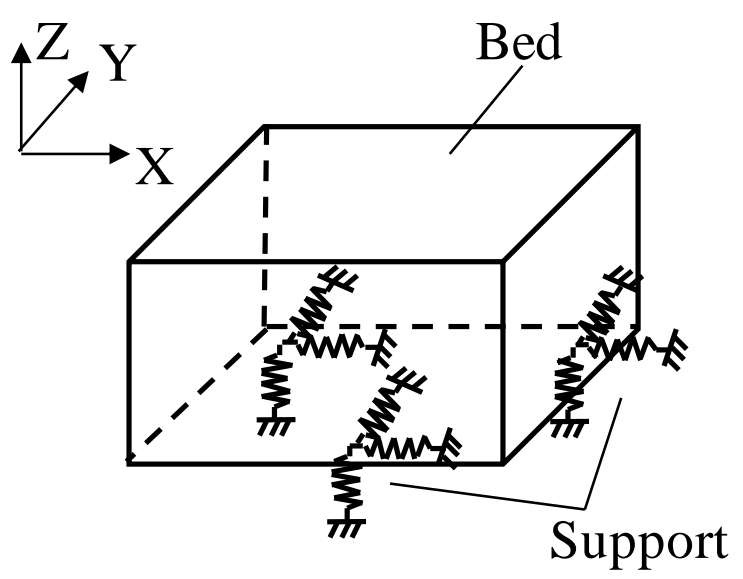

Fig. 16 Rigid body model used in the estimation 

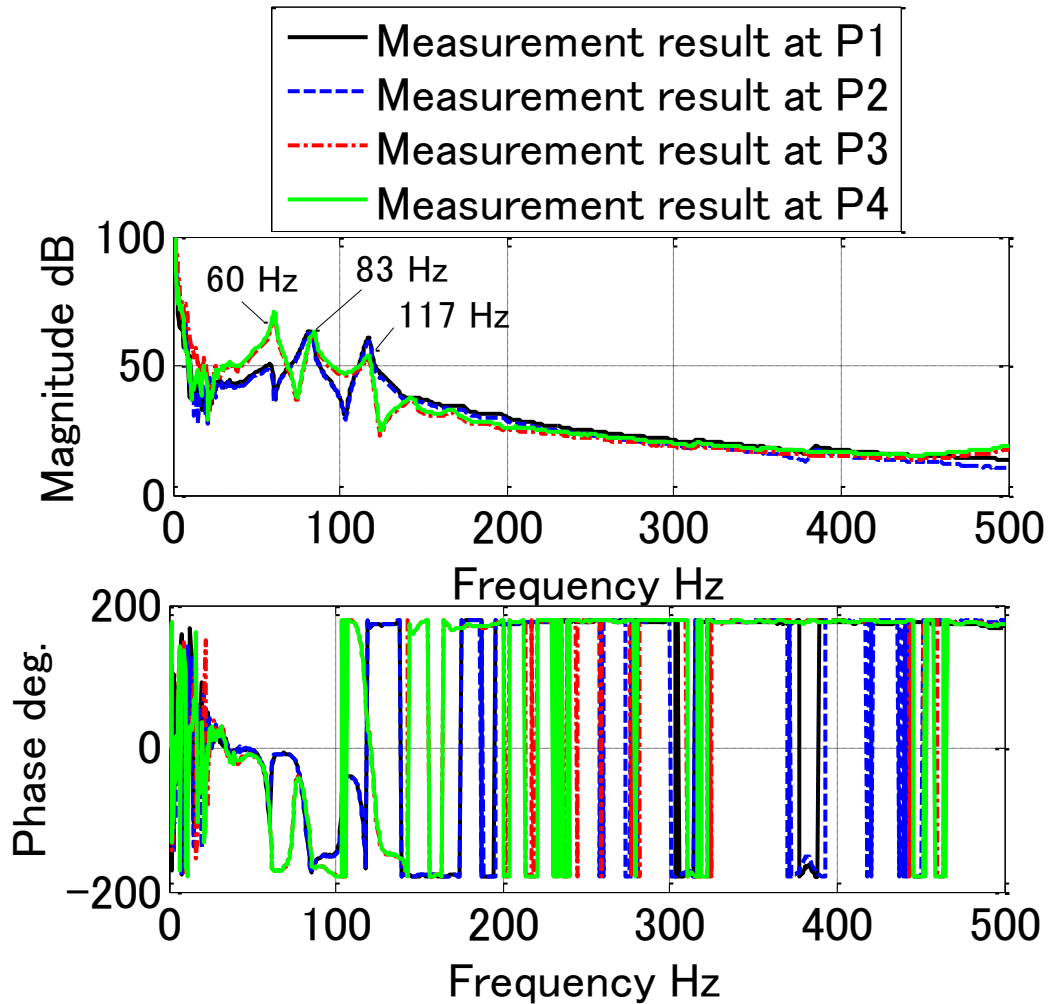

Fig. 17 Frequency response between the excitation force in the $\mathrm{Y}$ direction and the displacement in the $\mathrm{Y}$ direction 

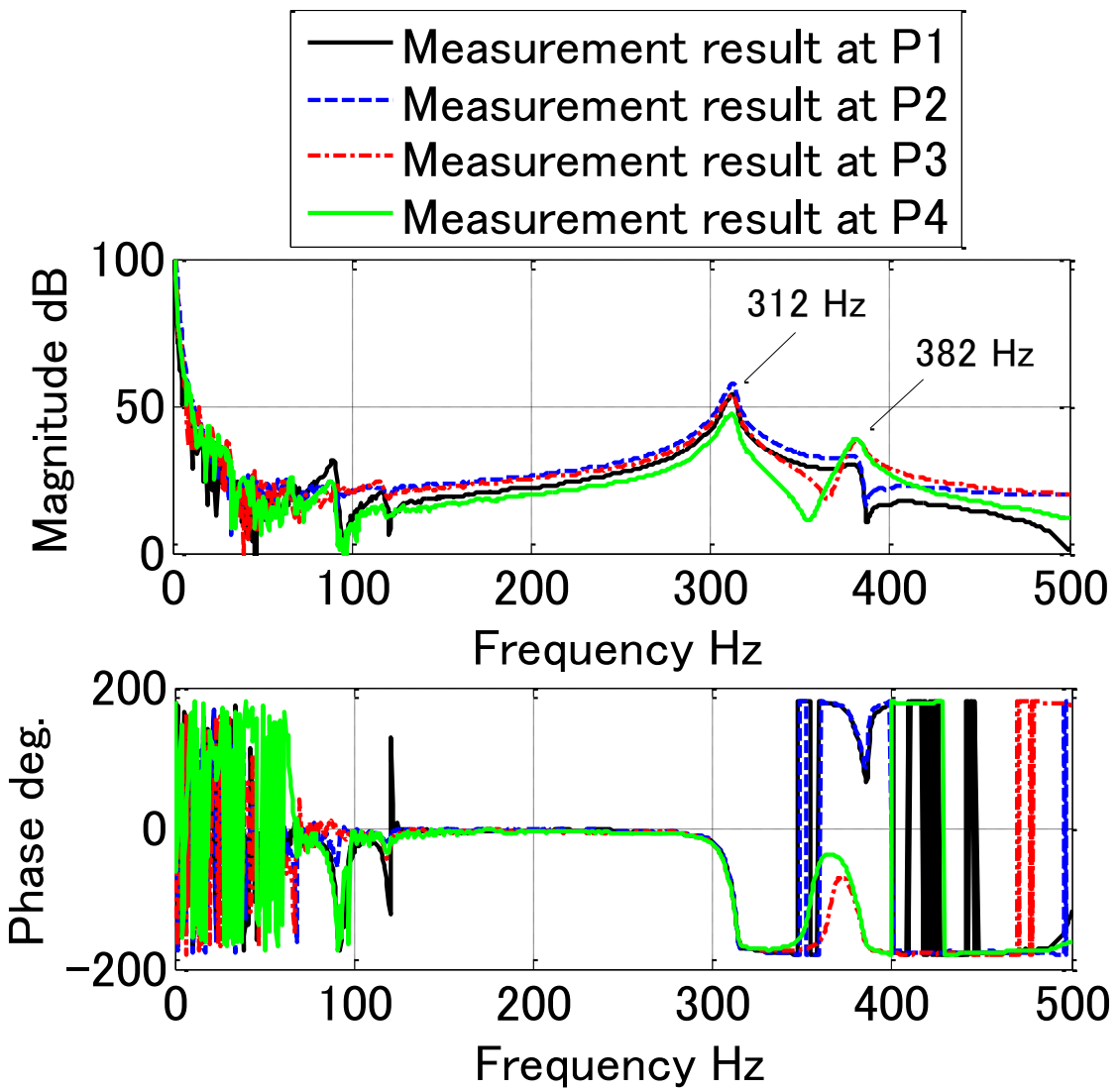

Fig. 18 Frequency response between the excitation force in the $\mathrm{Z}$ direction and the displacement in the $\mathrm{Z}$ direction 